\title{
Socialização econômica: conhecendo o mundo econômico das crianças
}

\author{
Iani Dias Lauer-Leite \\ Universidade Federal da Bahia \\ Celina Maria Colino Magalhães \\ Universidade Federal do Pará \\ Eulina da Rocha Lordelo \\ Universidade Federal da Bahia \\ Irani Lauer Lelis \\ Universidade Federal do Pará
}

\begin{abstract}
Resumo
O aprendizado de conceitos econômicos e os comportamentos econômicos de crianças são objetos de estudo da Socialização Econômica, uma área que tem atraído a atenção de pesquisadores, tanto da Psicologia do Desenvolvimento quanto da Psicologia Econômica. Os estudos têm aumentado significativamente nos últimos anos em outros países, mas no Brasil poucas pesquisas têm sido desenvolvidas. Este artigo objetiva apresentar a socialização econômica como uma área de pesquisa promissora e em franco desenvolvimento, mediante a discussão de três questões fundamentais inerentes à área: 1) As fases de desenvolvimento do pensamento econômico, 2) Variáveis que interferem na socialização econômica e 3) Comportamentos econômicos de crianças. No decorrer do artigo são evidenciados os principais resultados que pretendem responder às questões citadas e são mencionadas as lacunas a preencher, como possibilidades de pesquisas a realizar. Finaliza-se com sugestões para uma agenda brasileira de pesquisas.
\end{abstract}

Palavras-chave: socialização econômica; comportamentos econômicos; estágios do raciocínio econômico.

\begin{abstract}
Economic Socialization: knowing the children's economic world. The child's learning of economic concepts and economic' behaviors are subjects of economic socialization. The research in this area is increasing in the recent years but in Brazil there are a few studies only. This article aims to introduce economic socialization as a promising research area, through discussion of three questions: 1) stages of economic reasoning development, 2 ) variables that interfere in economic socialization and 3) children's economic behaviors. The article shows the most important results that try to answer those questions, points out some lacks to filled in and future investigations. Finally suggestions are presented for a Brazilian research agenda.
\end{abstract}

Keywords: economic behaviors; economic socialization; stages of economic reasoning.

$\mathrm{A}$ vida econômica das crianças foi ignorada por um bom tempo. Os estudos de Strauss $(1952,1954)$ nos Estados Unidos e Danziger (1958) na Austrália foram os primeiros realizados na área, e mediante tais estudos verificouse que as idéias das crianças sobre os temas econômicos eram diferentes das idéias dos adultos. A partir dos anos 70, vários estudos foram desenvolvidos na Psicologia do Desenvolvimento (Berti, 1992; Berti \& Bombi, 1988; Berti, Bombi, \& De Beni, 1986; Bombi, 1991; Flouri, 2004) e na Psicologia Econômica (Bonn \& Webley, 2000; Furnham, 1999; Webley \& Pugh, 2000). Os temas incluíram tópicos como dinheiro, preço e lucro, mesada, consumo infantil, desigualdade social, valor econômico dos objetos. Segundo Lewis, Webley e Furnham
(1995), hábitos de gastar, guardar, investir, jogar e comprar são estabelecidos na infância ou adolescência e o seu entendimento possibilita a intervenção e melhora na formação econômica dos futuros consumidores. Para esses autores, portanto, o estudo da socialização econômica visa averiguar como as crianças aprendem conceitos econômicos, em que estágios, qual a influência dos pais e da escola, bem como das variáveis demográficas.

Este artigo pretende apresentar a Socialização Econômica como uma área de estudo promissora e desafiante para pesquisadores no Brasil. Para tal, retoma-se a definição de Lewis, Webley e Furnham (1995), na forma de questionamentos que, se respondidos, traçam um quadro atual e abrangente da 
área, a saber: 1. Como crianças aprendem sobre conceitos econômicos? 2. Quais os estágios de desenvolvimento? 3. Como o dinheiro afeta o comportamento das crianças? 4. Que variáveis demográficas afetam a Socialização Econômica? 5. Como os pais e a escola atuam na Socialização Econômica? O artigo se propõe a responder esses questionamentos mediante uma revisão não sistemática da literatura, prolífica em outros países, mas ainda incipiente no Brasil.

\section{O desenvolvimento do pensamento econômico}

Conceitos como dinheiro, banco, investimento, poupança, preço e lucro começam a ser aprendidos na infância, sendo melhor compreendidos na adolescência. $\mathrm{Na}$ idade adulta, espera-se que o sujeito compreenda não apenas os conceitos, mas também que eles estão inter-relacionados em um sistema, fazendo parte do mundo econômico.

O estudo das variáveis que interferem nesse processo de aprendizado econômico começou a acontecer a partir das primeiras pesquisas sobre o tema, quando verificou-se a divergência existente entre os conceitos econômicos de crianças e adultos. A partir dessa descoberta, vários estudos foram desenvolvidos com o objetivo de compreender as causas de tais diferenças. Verificou-se forte relação entre a idade da criança e a compreensão do mundo econômico. A progressão encontrada levou à proposição de fases do desenvolvimento do pensamento econômico, relativamente consensuais, principalmente na correlação entre idade e complexidade do pensamento econômico. A maioria das classificações teve como base teórica as fases do desenvolvimento cognitivo propostas por Piaget. Alguns autores, contudo, propuseram outras seqüências de desenvolvimento, como Danziger (1958) e Leiser (1983), utilizando outras teorias, como os esquemas e a meta-cognição.

Os estudos de Emler (Emler \& Dickinson, 1985; Emler, 1986; Emler, Ohana, \& Dickinson, 1990) são uma exceção no que concerne a fases do desenvolvimento, ao adotar a Teoria das Representações Sociais, de Moscovici, para embasar seus estudos. Para este autor, a socialização é um processo de aculturação e não apenas de crescimento cognitivo, pois é nas crenças compartilhadas no mundo social que se encontram reflexos da cultura à qual pertence o indivíduo. As pesquisas que utilizam as representações sociais como base teórica não podem ser consideradas frontalmente opostas àquelas que têm como base as fases de desenvolvimento, pois ambas evidenciam que não é apenas a maturidade cognitiva que permite à criança entender o mundo econômico, mas também as representações sociais presentes na realidade dessa criança (Bonn \& Webley, 2000)

A primeira proposta de fases do desenvolvimento do pensamento econômico veio de um estudo realizado em 1952 por Strauss, com crianças de quatro a 11 anos. Elas foram entrevistadas e suas respostas classificadas em nove estágios, usando as idéias de Piaget. Os resultados mostraram que a criança parte do primeiro estágio, em que acredita poder comprar qualquer coisa com dinheiro, até o estágio final, em que ela entende a complexidade do mundo econômico.

Após essa primeira classificação, várias outras foram propostas por outros pesquisadores com base em pesquisas realizadas em diferentes culturas, utilizando como método entrevistas e questionários. Muitos estudos utilizaram como método apenas entrevistas clínicas (por exemplo: Burris, 1983; Strauss, 1952); em alguns casos, como nos estudos de Bert e Bombi (1988), Leiser (1983), e Denegri Coria (2010), questionários também foram usados. As amostras pesquisadas pertenciam a diferentes países como: Estados Unidos (Burris, 1983), Austrália (Danziger, 1958), Itália (Berti \& Bombi, 1988), Israel (Leiser, 1983) e Chile (Denegri Coria, 2010). Os resultados apresentaram convergência quanto à seqüência cronológica média do desenvolvimento do pensamento econômico A questão mais importante não se refere, portanto, às divergências quanto ao número de fases, mas à existência das fases e aos pensamentos e comportamentos similares encontrados em determinadas faixas etárias. Na figura 1 são mostrados os principais estudos que deram origem às seqüências de desenvolvimento.

Berti (1991) realizou uma análise das fases propostas pelos autores e apresentou uma síntese do pensamento típico de cada fase, ressaltando que as idades indicadas não devem ser tomadas

Tabela 1

Caracterização dos estudos sobre socialização econômica segundo o país, ano, idade dos sujeitos, temas e fases de desenvolvimento

\begin{tabular}{|c|c|c|c|c|c|c|}
\hline Pesquisador & País & Ano & $\mathrm{N}$ & Idade & Temas pesquisados & Fases \\
\hline Strauss & EUA & 1952 & 66 & $4,8-11,6$ & $\begin{array}{l}\text { Compra/venda, dinheiro, } \\
\text { produção e comércio }\end{array}$ & 9 \\
\hline Danziger & Austrália & 1958 & 41 & $5-8$ & $\begin{array}{l}\text { Negócio, "chefe", riqueza e } \\
\text { pobreza }\end{array}$ & 4 \\
\hline Burris & EUA & 1983 & 96 & $4,5-12$ & $\begin{array}{l}\text { Mercadorias, preço, } \\
\text { compra/venda, trabalho, } \\
\text { lucro }\end{array}$ & 3 \\
\hline Leiser & Israel & 1983 & 89 & $7-17$ & $\begin{array}{l}\text { Preço, pagamento, banco, } \\
\text { inflação }\end{array}$ & 3 \\
\hline Berti\&Bombi & Itália & 1988 & 100 & $3-8$ & $\begin{array}{l}\text { Trabalho, pagamento, } \\
\text { dinheiro, mercadoria, } \\
\text { compra/venda, propriedade. }\end{array}$ & 4 \\
\hline Denegri & Chile & 2000 & 150 & $6-16$ & $\begin{array}{l}\text { Dinheiro, pagamento, } \\
\text { banco, agentes econômicos }\end{array}$ & 3 \\
\hline
\end{tabular}


"ao pé da letra", pois são apenas um retrato da "criança tipo", havendo flexibilidade para que a criança esteja em uma fase posterior ou anterior.

Antes dos quatro anos, a criança não entende a utilidade do dinheiro. Portanto, a primeira fase ocorre entre quatro e cinco anos, quando a criança começa a entender que o dinheiro serve para fazer aquisições e que algumas coisas são compráveis e vendáveis, embora essas noções sejam ainda distorcidas e não realistas. Essa fase corresponde ao período pré-operacional de Piaget, mais precisamente o sub-estágio intuitivo, quando a criança aprende um modo de lidar com problemas, embora ainda sem uma clara representação conceitual (Baldwin, 1980). Surgem, também, as primeiras idéias sobre produção. Para a criança dessa fase o negociante produz o bem, cultiva as frutas e verduras que vende, ou constrói o que vende com materiais não mais usados.

Outra idéia comum nessa fase é que o negociante compra de outro negociante, que, por sua vez, compra de outro e assim sucessivamente, não se chegando à produção do bem. $\mathrm{O}$ dinheiro é visto como indispensável à compra, mas ainda não há a compreensão do motivo de haver vários tipos de dinheiro, como papel e metal. Não há entendimento sobre preços e valores monetários e de que cada produto tem um preço próprio, sendo necessário pagar aquele valor específico, e não qualquer dinheiro. Obter o dinheiro também é visto como algo fácil, bastando apenas buscá-lo no banco, na fábrica ou no escritório. O trabalho não é visto como uma atividade retribuída, ao contrário, as pessoas trabalham apenas porque é preciso. As crianças ainda não entendem o que é troco, por não entenderem o valor específico de determinada mercadoria e da diferenciação dos valores do dinheiro.

A segunda fase ocorre a partir dos seis/sete anos de idade, correspondendo ao estágio operacional concreto que, segundo Piaget, caracteriza-se pela aquisição de operações lógicoaritméticas e espaciais, embora restritas à compreensão de operações concretas. Agora começa a ocorrer uma discriminação das características do dinheiro. A criança percebe que existem notas ou moedas que valem mais que outras, e que os objetos à venda têm valores diferentes, determinados por características como dimensão, utilidade e beleza. Contudo, nessa fase há apenas a discriminação da idéia de mais e menos dinheiro. Por isso, não é possível comprar determinado objeto que custa $\mathrm{X}$, se as notas que o comprador tem são maiores que o valor do objeto, ou seja, o troco ainda é algo confuso. Em se tratando do trabalho, começa a se estabelecer uma compreensão incipiente da sua relação com o dinheiro.

A terceira fase ocorre ainda no estágio operacional concreto. Com a aquisição das habilidades matemáticas entre 7 e 10 anos, a criança é capaz de entender o que é o troco. Ela também compreende que o banco não é apenas a fonte de dinheiro de onde todos podem obtê-lo indistintamente, e que o dinheiro retirado no banco foi antes depositado por outras pessoas, para protegê-lo de ladrões. Além disso, o dinheiro não é dado, é apenas emprestado. Também há a diferenciação dos papéis de produtor e comerciante e a introdução do papel do atravessador. Na produção, a matéria natural substitui materiais de reciclagem e materiais não usados como matéria-prima para produção. Mas, em relação ao preço dos objetos, ainda permanece a idéia de que este é definido pelas qualidades intrínsecas do objeto, independentemente do custo de produção e de comercialização. Não há entendimento da lei da oferta e da procura. No caso de aumento da procura, a criança pensa que o preço deveria diminuir, assim todos poderiam comprar, o que é contrário às leis econômicas. O trabalho nessa fase é visto como a única forma correta de obter dinheiro. No entanto, as regras que regem o trabalho ainda são equivocadas, baseando-se na correspondência entre duração ou fadiga causada pelo trabalho e o valor do salário. Para a criança, o chefe de um grupo de trabalho é aquele que manda e paga os trabalhadores.

$\mathrm{Na}$ quarta fase, depois dos 10 anos, a criança começa a entender que os diversos conceitos e atores econômicos são parte de um mesmo sistema, dito econômico, no qual as pessoas exercem diferentes papéis. $\mathrm{Na}$ teoria de Piaget essa fase coincide com o final do estágio das operações concretas e a transição para o estágio operacional formal, caracterizado pelo raciocínio com possibilidades abstratas e a capacidade de analisar relações lógicas entre variáveis. Em se tratando do pensamento econômico, a criança afirma que o dinheiro pago aos trabalhadores é obtido da venda de produtos ou serviços, assim como entende que o preço dos produtos é uma soma do valor de custo e da comercialização. Compreende que a mudança de preços depende da lei da oferta e da procura, contudo, a compreensão dessa lei ainda não é plena, conforme Berti (1991). Para confirmar essa afirmativa, os resultados encontrados em um estudo realizado por esta autora mostraram alguns sujeitos de 13 anos relutantes em admitir que o preço aumentaria caso a procura aumentasse.

Denegri Coria (2010) comentou que, apesar de nessa fase o sujeito ter condições de pensar de maneira abstrata sobre o mundo econômico, permanecem algumas lacunas que são preenchidas com informações específicas sobre determinados processos, como por exemplo, os processos bancários.

A progressão de fases do pensamento econômico foi encontrada em vários estudos, em diferentes países. Contudo, ao retomar a idéia de Emler e colaboradores, de que a socialização é também um processo de aculturação e não apenas de desenvolvimento cognitivo, observa-se uma carência de estudos que busquem compreender como natureza e ambiente interagem para produzir desenvolvimento nesse aspecto. Uma exceção à regra refere-se ao trabalho de Leiser, Roland-Lévy e Sevòn (1991), que realizaram um estudo transcultural em doze países, objetivando verificar o entendimento, razões e atitudes das crianças sobre o mundo econômico. Os resultados apontaram para uma possível integração entre os pontos de vista cognitivo-desenvolvimental e a perspectiva construcionista. Observou-se que o entendimento de processos econômicos e de instituições como bancos, impostos e lucro progride em estágios, embora com forte influência da cultura. Já as representações e crenças econômicas sobre questões como riqueza, pobreza e desigualdade mostraram uma grande diversidade cultural e influência do individualismo, da sociedade e da família.

Para responder, pelo menos em parte à questão, um estudo realizado por Leiser, Roland-Lévy e Sevòn (1991) trouxe alguns insumos. Esse estudo transcultural foi realizado em doze países, objetivando verificar o entendimento, razões e 
atitudes das crianças sobre o mundo econômico. Os resultados apontaram para uma possível integração entre os pontos de vista cognitivo-desenvolvimental e a perspectiva construcionista. Observou-se que o entendimento de processos econômicos e de instituições como bancos, impostos e lucro progride em estágios, embora com forte influência da cultura. Já as representações e crenças econômicas sobre questões como riqueza, pobreza e desigualdade mostraram uma grande diversidade cultural e influência do individualismo, da sociedade e da família.

A influência da família, citada no estudo de Leiser, RolandLévy e Sevòn (1991), e outras variáveis não citadas nesse estudo como o gênero, a classe social e a escola têm sido averiguada em outras pesquisas. Os resultados encontrados e as perspectivas de estudo em relação a essas variáveis são analisadas a seguir.

\section{Variáveis que afetam a socialização econômica}

Nesse tópico são incluídas as variáveis demográficas, sócioeconômicas e, especificamente, como os pais e a escola atuam na socialização econômica.

\subsection{Idade}

Em vários estudos foi observada uma diferença significativa na compreensão de conceitos econômicos de crianças de diferentes idades. Em um estudo clássico, Burris (1983), objetivou comparar o entendimento do valor econômico de objetos por crianças inglesas de três grupos de idades. Para isso, ele analisou características que tornavam os objetos vendáveis ou não vendáveis e o que definia o valor econômico desses objetos. Os resultados mostraram que crianças mais novas classificaram itens como vendáveis ou não vendáveis de acordo com características físicas dos produtos. Também o valor econômico dos objetos foi dado de acordo com características físicas, como o tamanho, por exemplo. Crianças do grupo de 7-8 anos relacionaram o valor do objeto à sua utilidade. Aos 10-12 anos o valor dos objetos estava ligado a fatores envolvidos na produção, como o tipo de material usado. O grupo de maior idade apresentou explicação mais complexa para o valor dos objetos, embora ainda imperfeita.

Diferenças entre idades também foram observadas por Berti e Bombi (1988) em um estudo na Itália, sobre pagamento pelo trabalho realizado com 100 crianças de três a oito anos. A maior parte das crianças de três a cinco anos não estabeleceu conexão entre trabalho e dinheiro. Algumas crianças de 4-5 e de 5-6 anos conseguiram estabelecer uma conexão primária entre trabalho e dinheiro ao afirmarem que apenas o trabalho do pai era pago. A maioria das crianças de 5-8 anos reconheceu que outros trabalhos eram pagos, vindo do trabalho o dinheiro.

Assim, há consenso quanto à diferenciação de pensamento econômico e comportamento econômico de crianças segundo a idade, bem como a progressão conforme o aumento de idade. Não se pode afirmar, entretanto, que apenas o fator biológico seja responsável pelas mudanças. Nesse sentido há necessidade de mais estudos que contemplem esse tópico.

\subsection{Gênero}

Existem diferenças de gênero tanto na compreensão dos conceitos, como no comportamento econômico. Rinaldi e
Giromini (2001) estudaram esse tópico com crianças italianas de 8-18 anos. Os resultados indicaram que as meninas não se sentiram à vontade para falar sobre dinheiro, com menos conhecimento dos assuntos abordados. Por sua vez, os meninos falaram mais sobre guardar dinheiro e sobre o Euro. As autoras explicaram essas diferenças pela influência dos pais, que falavam mais com os meninos sobre questões econômicas, e pela dificuldade das meninas com a disciplina matemática.

Também foram observadas diferenças de gênero no comportamento econômico. Furnham (1999) realizou um estudo sobre guardar e gastar dinheiro na Inglaterra, com 280 crianças entre 11 e 16 anos. Os meninos receberam $20 \%$ a mais que as meninas na mesada em pagamento por serviços e como presente de aniversário. As meninas foram mais conservadoras, menos ativas economicamente e menos interessadas no assunto, enquanto os meninos foram mais assertivos e crédulos no sistema econômico. Segundo Furnham (1999) essas diferenças poderiam estar ligadas ao sistema de crenças, mas essa é uma questão inexplorada na área, pois não se sabe se as diferenças encontradas são culturais e se estão vinculadas aos estereótipos de gênero, aos valores ou à educação parental.

\subsection{Classe social}

Estudos em classe social têm apresentado resultados divergentes, possivelmente pela complexidade na determinação da classe. As pesquisas na área têm usado freqüentemente a profissão dos pais para classificar os sujeitos. Um segundo fator se refere aos resultados das próprias pesquisas, que mostram diferenças entre sujeitos da mesma classe, sugerindo que essa variável pode não ser o fator mais significativo.

Leahy (1983) realizou um estudo com 700 crianças inglesas em quatro grupos de idade, das classes média-alta e baixa, objetivando analisar explicações e justificativas para os conceitos "mobilidade social" e "mudança". Os resultados mostraram que crianças mais novas explicavam a mobilidade social mediante doação de dinheiro aos pobres; crianças mais velhas explicaram a mobilidade em termos de mudança na estrutura social; adolescentes da classe baixa afirmaram que os ricos eram resistentes à mobilidade social e crianças da classe média alta afirmaram que a pobreza não poderia ser mudada e era resultado de dívidas e desperdício de dinheiro. O estudo mostrou que a classe social é uma variável que interfere nas explicações econômicas, mas há interação entre essa variável e outras, como idade, em se tratando das explicações para a mobilidade social.

Bombi (1991) reviu os estudos de Furnham (1982) e de Emler e Dickinson (1985) relacionados à classe social e que usaram a profissão paterna e o tipo de escola freqüentada pela criança como fatores determinantes da classe social. No estudo de Furnham (1982), conduzido na Inglaterra, foram pesquisadas concepções sobre pobreza com sujeitos adolescentes e os resultados apontaram dois tipos de explicações: individualistas e sociais. As primeiras viam a pobreza como resultado da própria ação/não-ação do indivíduo, enquanto as explicações sociais atribuíam às instituições a responsabilidade pela situação econômica dos indivíduos. Os resultados dessa pesquisa demonstraram que adolescentes de classe média e alta deram explicações individualistas para a pobreza e a riqueza, enquanto 
aqueles de classe baixa preferiram explicações mais sociais.

Por outro lado, ao analisar os resultados de Emler e Dickinson (1985), Bombi (1991) concluiu que a classe social faz parte de uma variável mais complexa, chamada espaço de vida, que abarca as informações e experiências acessíveis ao sujeito; essa variável teria influência significativa sobre a formação dos conceitos econômicos.

\subsection{Espaço de vida}

O espaço de vida é compreendido como ambientes: a casa, a escola, o país. Os estudos definidos por essa perspectiva priorizam a identificação de experiências específicas relevantes na construção da realidade econômica infantil em uma determinada idade; no espaço de vida das crianças, portanto, a pesquisa prioriza a análise de situações naturais, renunciandose ao controle completo das variáveis (Bombi, 1991). A noção de espaço de vida é análoga à de nicho de desenvolvimento, proposta por Super e Harkness (1986).

Nesse contexto, Berti e Bombi (1990) fizeram um estudo sobre produção e distribuição de produtos agrícolas e industriais com crianças da cidade e da montanha. As autoras relataram que crianças pequenas acreditavam na pré-existência de produtos. Crianças médias sabiam que era necessário produzir, mas não entendiam como. Crianças maiores entendiam que os produtos acabados vinham da matéria-prima encontrada na natureza, sugerindo uma progressão da ausência de idéias de como a produção se dava até o estágio final, na qual havia identificação correta dos produtores. As crianças seguiram a mesma progressão no entendimento dos conceitos econômicos, porém, apresentaram ritmos diferentes, segundo o ambiente de vida e o produto pesquisado. Crianças da montanha tiveram dificuldades em explicar a produção de produtos industriais e facilidade para explicar a de produtos agrícolas, o contrário das crianças da cidade.

Outro estudo realizado pelas mesmas autoras e citado por Bombi (1991), quanto à proveniência do dinheiro, mostrou resultados um pouco diferentes. $\mathrm{O}$ estudo foi realizado com um grupo de crianças italianas de quatro a 10 anos de idade, filhos de artesãos, pequenos hoteleiros e comerciantes, que tinham oportunidades de observar a relação dos pais com os clientes. Mesmo com essas experiências, houve crianças nessa amostra que afirmaram que o banco dava dinheiro a qualquer pessoa, bastaria pedir. Há evidência, portanto, de que diferentes fatores interagem para produzir o aprendizado: a observação da atividade econômica dos pais, a idade da criança, sua habilidade cognitiva e o ambiente no qual está inserida são fatores preponderantes para o desenvolvimento do pensamento econômico.

\subsection{Como os pais atuam na socialização econômica}

$\mathrm{Na}$ infância, os pais instalam nos filhos suas próprias crenças sobre economia, mediante recompensas e sanções (Lunt \& Furnham, 1996), assim como "mensagens" sobre aspectos econômicos da vida transmitidas dos pais para os filhos que influenciam nas concepções que estes têm mais tarde. Furnham e Argyle (1998, p. 68) escreveram sobre um clínico que pediu a seus pacientes que relatassem mensagens econômicas passadas dos pais para eles. Algumas delas foram: "Minha mãe disse que apenas pessoas pobres iam para o céu”, "Meus pais disseram que eu era uma criança popular porque eles eram ricos... Eles me disseram... se alguém estivesse sem dinheiro, estaria sem amigos", "Meus pais disseram que havia um segredo para fazer dinheiro, mas ninguém em nossa família sabia como era". $\mathrm{O}$ fato de as pessoas entrevistadas lembrarem com exatidão das frases que lhes foram ditas é um indicador da influência parental sobre a vida econômica das crianças em anos subseqüentes. As vivências iniciais incluem o contato com o dinheiro, que pode acontecer de maneira direta ou indireta, quando elas vêem seus pais comprando ou vendendo coisas, quando recebem mesada. Por esse motivo, o tema mesada tem sido bastante estudado, tanto com pais quanto com filhos.

Marshall e Magruder (1960) apresentaram o primeiro estudo que investigou a relação entre práticas educacionais concernentes a dinheiro e conhecimento e uso do dinheiro por crianças. Os resultados mostraram que o conhecimento do dinheiro está diretamente relacionado à extensão da experiência da criança: se ela tem dinheiro para gastar, se tem oportunidades para ganhar e poupar, bem como os hábitos e atitudes dos pais quanto ao gasto. Em outro estudo realizado, Marshall (1964) encontrou resultados que mostraram que o conhecimento financeiro não diferia entre crianças que recebiam ou não mesada.

Mais recentemente Webley e Nyhus (2006) reportaram os resultados de um estudo com sujeitos de 16 a 21 anos e seus pais, cujo objetivo foi averiguar a influência do comportamento dos pais sobre o comportamento econômico dos filhos e suas orientações futuras. Os resultados mostraram que o comportamento econômico parental, como discutir assuntos financeiros com os filhos e as orientações parentais, por exemplo, em relação à orientação quanto ao futuro, tiveram um impacto fraco, mas claro sobre o comportamento econômico dos filhos.

Dessa forma, os resultados dos três estudos citados apontam o recebimento do dinheiro, seja ele proveniente de mesada ou não, e o acesso à experiência como fatores que promovem o conhecimento econômico. Ambos os fatores são comumente proporcionados pelos pais/cuidadores da criança, tornando-se relevante analisar crenças e comportamentos dos pais quanto ao "dinheiro dos filhos".

Furnham (2001), por exemplo, realizou um estudo com 300 pais britânicos com o objetivo de verificar determinantes de atitudes, crenças e valores parentais quanto à mesada. Os resultados de uma análise fatorial realizada para averiguar as atitudes parentais quanto à mesada apresentaram seis fatores: envolvimento parental/educação, regras fixas, veto parental, fator draconiano (pagamento de juros sobre empréstimos tomados), regularidade da mesada e liberalismo parental.

Limites, liberalismo parental, propósitos e definição da mesada foram analisados em um estudo qualitativo por Baele e Vlerik (2000) na Bélgica, com mães e filhos entre 6 e 12 anos. A mesada foi definida pelas mães como um "dinheiro dado regularmente, com data fixa e quantia fixa, sobre a qual as crianças têm livre controle e que pode ser gasto imediatamente ou ser guardado para comprar algo grande e muito caro" (p.37).

Limites também foram estudados por Wronski (1999) no Brasil, em um estudo qualitativo com pais de crianças entre 7 e 12 anos, analisando as tomadas de decisão de consumo infantil. 
$\mathrm{Na}$ categoria responsabilidade da criança, os pais avaliaram o comportamento dos filhos de duas maneiras: comportamento geral responsável ou despreocupado. Em se tratando da freqüência da solicitação de consumo, três foram os tipos: comportamento de consumo persistente, vago e desinteressado. A maioria dos pais afirmou que seus filhos apresentavam comportamento de consumo persistente. Os limites também apareceram como uma categoria, em termos de relevância da solicitação de compra. A autora observou que a maioria dos pais cedia aos pedidos dos filhos, independentemente da avaliação acerca da sua responsabilidade e da relevância da solicitação, evidenciando uma incongruência entre as afirmações e as práticas dos pais.

Em síntese, a literatura aponta alguns fatores comuns que compõem as crenças parentais quanto à mesada ou de maneira mais abrangente, ao "dinheiro dos filhos": a definição, função, limites e regras. Alguns estudos mostraram incongruência entre algumas crenças dos pais e suas práticas (por exemplo, Wronski, 1999). É possível que pesquisas abarcando pais e filhos como participantes, a exemplo da reportada por Webley e Nyhus (2006), possam clarificar essa questão e outras, como o melhor entendimento do impacto do significado do dinheiro sobre o comportamento econômico dos filhos.

\subsection{Como a escola atua na socialização econômica}

Furnham e Argyle (1998) afirmaram que o estudo de “diferentes aspectos da compreensão e percepção de crianças sobre a economia, suas atitudes quanto ao dinheiro e as posses, seus hábitos de gastos e consumo são relevantes para o ensino de princípios econômicos em escolas, assim como para pesquisa em Psicologia" (p.63). Apesar do interesse para psicólogos e educadores, não foram encontrados muitos estudos que mostrassem o papel da escola na socialização econômica.

Destaca-se a pesquisa/intervenção realizada por Roos et al. (2005), sobre o entendimento de conceitos econômicos específicos antes e após a implantação de um programa de ensino desses conceitos para 23 crianças de uma pré-escola na África do Sul. O programa foi realizado durante uma semana e 20 conceitos econômicos foram apresentados às crianças, dentre eles, dinheiro, ganho, gasto e poupança. A experiência produziu um aumento de 30 para $60 \%$ no entendimento dos conceitos econômicos e um aumento de 52 para $64 \%$ na identificação destes mesmos conceitos.

À guisa de conclusão, Roos et al. (2005) apresentaram duas possíveis justificativas para o não alcance de $100 \%$ na identificação e no entendimento dos conceitos pesquisados: tempo de realização do programa, que foi de apenas uma semana; para futuras pesquisas, poder-se-ia testar os mesmos conceitos com um programa mais expandido. A segunda explicação referese aos limites impostos pela habilidade cognitiva de crianças da faixa etária estudada, uma hipótese a ser considerada em futuros estudos.

\section{Comportamento econômico das crianças}

Foram revistos estudos que versam sobre três comportamentos específicos: poupar, consumir e emprestar/pedir emprestado. No entanto, subjacente a estes comportamentos está o "ganhar". Como as crianças ganham dinheiro? Furnham e Thomas (1984) e Leiser e Ganin (1996) relataram as maneiras pelas quais as crianças recebem dinheiro: 1) Os pais dão dinheiro quando as crianças precisam; 2) Mesada com valor e data fixos; 3 ) Compensação por trabalhos realizados fora de casa; 4) Compensação por trabalhos realizados em casa; e 5) Dinheiro recebido por familiares como presente em ocasiões especiais. A partir do ganho, as crianças se comportam economicamente.

Furnham (1999) realizou na Inglaterra um estudo com 280 crianças entre 11 e 16 anos, objetivando verificar seus hábitos de guardar e gastar dinheiro, mediante questionário. Os resultados mostraram que $90 \%$ dos participantes recebiam dinheiro, $70 \%$ eram provenientes de mesada. Quanto a guardar e gastar propriamente, 72,5\% emprestavam dinheiro a amigos, 54,25\% pediram emprestado e $92 \%$ afirmaram ter dinheiro guardado. A razão mais comum para guardar dinheiro foi para comprar algo especial. Cerca de $70 \%$ dos participantes afirmaram ter conta no banco. As razões para manter o dinheiro no banco foram: para guardar o dinheiro em segurança, para obter lucros, porque os pais orientaram a abrir a conta e porque o banco oferecia um plano especial para crianças e adolescentes.

Um segundo estudo focalizando o comportamento econômico de crianças foi realizado no Brasil por Ballvè (2000), objetivando analisar a experiência do consumo de crianças entre sete e 11 anos, utilizando o método etnográfico para coleta de dados. Os resultados mostraram que quase todas as crianças recebiam mesada e guardavam-na para comprar algo importante, embora não soubessem ainda o quê. A poupança foi vista como importante, tanto para comprar algo maior, quanto para prevenção de dificuldades financeiras. Em relação ao manejo do dinheiro, as crianças relataram estabelecer parcerias com os pais, quando o próprio dinheiro não era suficiente.

Quanto ao consumo propriamente, foi observado que as crianças pesquisadas constituíam um grupo bem informado e confortável com os aspectos da vida moderna como instantaneidade, tecnologia e individualismo, contudo, ainda mantinham o sentimento de "ser criança". Para essas crianças, cada fase da vida foi vista como uma fase fechada, na qual o indivíduo deve adaptar-se e gostar das coisas próprias daquela idade, não sendo vistos com bons olhos aqueles que desejam e usam coisas consideradas de outra fase.

Nos estudos citados, percebe-se certas peculiaridades. No estudo de Furnham (1999) observou-se o uso do banco pelas crianças, algo que não aparece nos estudos brasileiros. Quanto às similaridades, os estudos de Furnham (1999) e Ballvè (2000) mostraram crianças bem informadas economicamente, mesmo vivendo realidades bem distintas. Essas similaridades e diferenças mostram a necessidade de se pesquisar mais, principalmente no Brasil, para descobrir universalidades e especificidades no comportamento econômico de crianças.

\section{Perspectivas futuras e considerações finais}

O mundo econômico é visto de maneira diferente pelas crianças, em relação à visão do adulto e à própria realidade. A socialização econômica preocupa-se em discutir três questões fundamentais: 1) A questão das fases de desenvolvimento do 
pensamento econômico; 2) As variáveis que interferem na socialização econômica e 3) Os comportamentos econômicos de crianças.

De acordo com o conhecimento acumulado quanto a essas três questões, está bem estabelecida a relação entre idade e complexidade do pensamento econômico, levando a crer que são necessários alguns pré-requisitos cognitivos para a plena compreensão do mundo econômico. Mas ainda resta saber quais variáveis promovem a mudança das primeiras impressões econômicas até aquelas corretas. Apesar dos avanços recentes, ainda existem muitas questões sem resposta, principalmente quanto à natureza da influência de diversas variáveis sobre o comportamento econômico de crianças; o que é específico e o que é universal; quais variáveis moldam o pensamento e comportamento econômico; o papel de fatores como desenvolvimento cognitivo, diferenças culturais, gênero, situação econômica, sociedade em que se vive, entre outras.

A agenda brasileira é ampla, dada a escassez de estudos no país, sendo necessária a averiguação das fases de desenvolvimento do pensamento econômico em primeiro lugar. Sugere-se avaliar os modelos propostos (ver quadro 1) com crianças brasileiras, em especial o modelo de fases de Denegri Coria (2010), dado que sua proposta foi baseada nos modelos anteriores e em trabalhos empíricos recentes. Além disso, sua teoria vem sendo testada com crianças da América Latina e é interessante averiguar similaridades e diferenças com amostras do Brasil. Esse modelo, resumidamente, propõe a existência de três níveis representantes de concepções econômicas globais: 1) pensamento préeconômico, que é subdividido em pensamento pré-econômico e pensamento econômico primitivo 2) pensamento econômico subordinado ou concreto e 3) pensamento econômico independente ou inferencial. A partir dessas fases alguns instrumentos que objetivam analisar diferentes aspectos da socialização econômica foram desenvolvidos pela autora e colaboradores.

No Brasil, alguns estudos têm sido desenvolvidos utilizando os materiais elaborados por Denegri Coria e colaboradores. Destacam-se os trabalhos realizados no Laboratório de Psicologia Genética da Unicamp, que estabeleceu uma linha de pesquisa denominada Educação Econômica e Teoria Psicogenética. Tal linha de pesquisa objetiva analisar os processos psicológicos subjacentes aos comportamentos econômicos, investigar o impacto da economia sobre os indivíduos e construir modelos de alfabetização econômica. Os trabalhos, ainda em desenvolvimento, utilizam a classificação proposta por Denegri Coria(2010) e visam, de forma geral, analisar o processo de aprendizado econômico de crianças, adolescentes e jovens.

Outra questão pertinente refere-se à identificação de relações entre conceitos econômicos e comportamentos econômicos. Nesse sentido, pesquisadores do Programa de Pós-Graduação em Teoria e Pesquisa do Comportamento, da Universidade Federal do Pará, vêm desenvolvendo, desde 2002, alguns trabalhos que objetivam clarificar a existência e natureza dessas relações.

Mais iniciativas como as citadas são necessárias, pois as variáveis analisadas brevemente neste artigo necessitam de estudos mais aprofundados, que objetivem mostrar, por exemplo, de que forma os pais influenciam a socialização econômica dos filhos e se o significado atribuído a determinado conceito econômico é transmitido de uma geração para outra. Também é preciso descobrir como o gênero interfere no comportamento econômico. Relações entre socialização econômica e variáveis não analisadas no artigo, como os valores individuais e o significado do dinheiro devem ser estudadas, pois em que medida os valores individuais e o significado atribuído ao dinheiro interferem na formação dos conceitos econômicos e nos comportamentos econômicos?

Espera-se que as questões suscitadas estimulem novas pesquisas e que o artigo indique possíveis caminhos que abarquem os temas em questão. Dada a diversidade cultural existente no país, propõe-se uma nova rota de pesquisas que contemple esse aspecto, ao tempo em que se busque entender o que é generalizado e o que é típico de cada cultura. Para a sociedade, os resultados propiciarão conhecimento que poderá ser usado pelos pais, pela escola e pelas instituições financeiras, no intuito de formar cidadãos conhecedores do mundo econômico em que vivem.

\section{Referências}

Baelle, A., \& Vlerick, P. (2000). Pocket money and saving behavior of children a qualitative study. In International Association for Research in Economic Psychology (Org.), 27th Annual Colloquium. Resumo (p.35-39). Baden, Alemanha.

Baldwin, A. (1980). Teorias de desenvolvimento da criança. São Paulo: Pioneira. Ballvé, F. D. (2000). A criança e a experiência do consumo: um estudo etnográfico em uma escola do Rio de Janeiro. (Dissertação de mestrado, Universidade Federal do Rio de Janeiro, Rio de Janeiro).

Berti, A. E. (1991). Le concezioni infantili sugli scambi economici: sequenze di sviluppo e modalità di apprendimento. In S. Zamagni, P. Legrenzi, A. E. B Berti, \& A. Ajello (Orgs.), Economia e processi di conoscenza (pp. 87-118). Torino: Loescher.

Berti, A. E. (1992). Acquisition of the profit concept by third-grade children. Contemporary Educational Psychology, 17, 293-299.

Berti, A. E., \& Bombi, A. E. (1988). The child's construction of economics. Cambridge: Cambridge University Press.

Berti, A. E., \& Bombi, A. E. (1990). Environmental differences in understanding production and distribution. In J. Valsiner (Org.), Child development in cultural context (pp.31-40). Toronto: Hogrefe \& Huber.

Berti, A. E., Bombi, A. S., \& De Beni, R. (1986). Acquiring economic notions: profit. International Journal of Behavioral Development, 9, 15-29.

Bombi, A. E. (1991). Sviluppo di nozioni economiche ed ambiente. In S. Zamagni, P. Legrenzi, A. E. B. Berti, \& A. Ajello (Orgs.), Economia e processi di conoscenza (pp. 87-118). Torino: Loescher.

Bonn, M., \& Webley, P. (2000). South African children's understanding of money and banking. British Journal of Developmental Psychology, 18, 269-278.

Burris, V. L. (1983). Stage in the development of economic concepts. Human Relations, 36(9), 791-812.

Danziger, K. (1958). Children's earliest conceptions of economic relationships. Journal of Genetic Psychology, 91, 231-240.

Denegri Coria, M. (2010). Introducción a la psicología económica. Recuperado de http://www.eumed.net/libros/2010b/681/

Emler, N. (1986). Perception of Occupation-related income differences in middle childhood: a cross-national comparison of class differences. Paper apresentado no 2nd European Congress of International Society for the Study of Behavioural Development, Roma, Itália.

Emler, N., \& Dickinson, J. (1985). Children's representation of economic inequalities: the effect of social class. British Journal of Developmental 
Psychology, 3, 191-198.

Emler, N., Ohana, J., \& Dickinson, J. (1990). Children's representation of social relations. In G. Duveen \& B. Lloyd (Orgs.), Social representations and the development of knowledge (pp. 47-69). Cambridge: Cambridge University Press.

Flouri, E. (2004). Childhood families of homeless and poor adults in Britain: a prospective study. Journal of Economic Psychology, 25, 1-14.

Furnham, A. (1982). The perception of poverty among adolescents. Journal of Adolescence, 5, 135-147.

Furnham, A. (1999). The saving and spending habits of young people. Journal of Economic Psychology, 20, 677-697.

Furnham, A. (2001). Parental attitudes to pocket money/allowances for children. Journal of Economic Psychology, 22, 397-422.

Furnham, A., \& Argyle, M. (1998). The Psychology of money. London: Routledge.

Furnham, A., \& Thomas, P. (1984). Pocket money: a study of economic education. British Journal of Developmental Psychology, 2, 205-212.

Leahy, R. (1983). Development of the conception of economic inequality II. Explanations, justifications and conceptos of social mobility and change. Develomental Psychology, 19(1), 111-125.

Leiser, D. (1983). Children's conceptions of economics: the constitution of a cognitive domain. Journal of Economic Psychology, 4, 297-317.

Leiser, D., \& Ganin, M. (1996). Economic participation and economic socialization. In P. Lunt \& A. Furnham (Orgs.), Economic Socialization: the economics beliefs and behaviours of young people. London: Edward Elgar.

Leiser, D., Roland-Levy, C., \& Sèvon, G. (1991). Children's economic socialization: Summarizing the cross-cultural comparison of ten countries. Journal of Economic Psychology, 11, 591-614.

Lewis, A., Webley, P., \& Furnham, A. (1995). The new economic mind. New Jersey: Prentice Hall.
Lunt, P., \& Furnham, A. (1996). Economic socialization. London: Elgar.

Marshall, H. (1964). The relation of giving children an allowance to children's money knowledge and responsibility, and to other practices of parents. Journal of Genetic Psychology, 104, 35-51.

Marshall, H., \& Magruder, L. (1960). Relations between parents money, educations practices and children's knowledge and use of money. Child Development, 31, 253-284

Rinaldi, E., \& Giromini, E. (2001). Money socialization tracks and gender differences: a study on italian children. In International Association for Research in Economic Psychology (Org.), XXVI Colloquium on Economic Psychology. Resumos (pp. 256 - 260). Bath, Inglaterra.

Roos, V., Chiroro, P., van Coppenhagen, C., Smith, I., van Heerden, E., Abdoola, R. E., ...Beukes, C. (2005). Money adventures: introducing economic concepts to preschool children in the South African context. Journal of Economic Psychology, 26, 243-254.

Strauss, A. (1952). The development and transformation of monetary meaning in the child. American Sociological Review, 17, 275-286.

Strauss, A. (1954). The development of conceptions of rules in children. Child Development, 25, 193-208.

Super, C., \& Harkness, S. (1986). The developmental niche: a conceptualization at the interface of society and the individual. International Journal of Behavioral Development, 9, 545-570.

Webley, P., \& Nyhus, E. K. (2006). Parents' influence on children's future orientation and saving. Journal of Economic Psychology, 27, 140-164.

Webley, P., \& Pugh, P. (2000). Adolescent participation in the U.K. national lottery games. Journal of Adolescence, 23, 1-11.

Wronski, A. V. (1999). Tomadas de decisão de consumo nas relações familiares infantis. (Dissertação de mestrado, Universidade Federal de Santa Catarina, Florianópolis).

Iani Dias Lauer-Leite, doutora em Teoria e Pesquisa do Comportamento (Psicologia - Universidade Federal do Pará-UFPA), é professora adjunta I do Instituto Multidisciplinar em Saúde Anísio Teixeira da Universidade Federal da Bahia - IMS/UFBA

Endereço para correspondência: Instituto Multidisciplinar em Saúde Anísio Teixeira - IMS/UFBA, Av. Olivia Flores, 3000, Vitória da Conquista - BA CEP: 45031-000

Telefone: (77) 999244 00. Fax: (77) 342400 93. E-mail: ianilauer@yahoo.com.br

Celina Maria Colino Magalhães, doutora em Psicologia - Ecoetologia pela Universidade de São Paulo USP, é professora associada II da Universidade Federal do Pará - UFPA

email: celina.magalhaes@pesquisador.cnpq.br

Eulina da Rocha Lordelo, pós-doutora pela Universidade de Stavanger, Noruega e doutora em Psicologia Experimental pela Universidade de São Paulo - USP, é professora associada da Universidade Federal da Bahia - UFBA. E-mail: eulina@ufba.br

Irani Lauer Lellis, doutoranda em Psicologia, no Programa de pós-graduação em teoria e pesquisa do comportamento, da Universidade Federal do Pará - UFPA, mestra em teoria pesquisa do comportamento pela mesma universidade, é bolsista do CNPQ.

E-mail: iranilellis@gmail.com 